\title{
Enfoques subnacionales y perspectivas comparadas de la dinámica política durante la transición democrática argentina
}

\author{
Reseña de Marcela Ferrari y Mónica Gordillo (Comps.), La reconstrucción \\ democrática en clave provincial, Rosario: Prohistoria Ediciones, 2015, 282 \\ páginas.
}

\section{Marisa A. Moroni *}

* Universidad Nacional de La Pampa -Instituto de Estudios Sociohistóricos (UNLPam-IESH) CONICET, Argentina I marisa moroni@yahoo.com.ar

La apertura política de principios de los años ochenta en Argentina propició el desarrollo de una historiografía que, en diálogo con otras disciplinas como las ciencias políticas y la sociología, comenzó a explicar el denominado proceso de "transición democrática”. En las últimas décadas, el debate académico se orientó a definir periodizaciones y proponer estudios comparativos para distinguir fases o etapas de la institucionalización democrática en América Latina y Argentina. Estas interpretaciones maduraron a la luz de las conceptualizaciones formuladas por Guillermo O 'Donnell (2002: 311-332) sobre las transiciones latinoamericanas y las "teorías de la consolidación democrática”. En el caso nacional, las expectativas que generó el nuevo escenario político o como señala Catalina Smulovitz (2010:9-11), “la ilusión del momento fundante”, desdibujó la pervivencia de actores y prácticas con importantes cuotas de poder y recursos para minar las bases del régimen democrático y alentar un clima de conflictividad social. Progresivamente, la agenda de investigaciones se complejizó y alcanzó a las distintas dimensiones de los estudios transicionales. Por un lado, se desplazó el foco de análisis hacia los procesos que se gestaron en la etapa previa al cambio institucional; por el otro, se incorporó la variable subnacional y comparativa para matizar la trayectoria centralista de estos estudios.

El libro La reconstrucción democrática en clave provincial de Marcela Ferrari y Mónica Gordillo, integra esta línea de estudios que identifica los acuerdos y tensiones en las prácticas políticas 
durante la reconstrucción democrática en los espacios provinciales (p.24). Las autoras interpretan los desafíos de los procesos políticos desarrollados en Buenos Aires y Córdoba, dos de los distritos electorales determinantes en los comicios nacionales de 1983. Los textos reunidos en esta obra registran las características organizacionales de los movimientos partidarios, sociales y sindicales en las provincias más pobladas del país, considerando la posición que ocuparon en la etapa previa a la democratización. La obra se divide en dos partes, la primera de ellas, "Reorganizaciones, normalizaciones e institucionalizaciones” está compuesta por tres capítulos que abordan la metamorfosis que protagonizan los partidos políticos y las agrupaciones sindicales, además de examinar las propuestas de reformas constitucionales en Córdoba y Mar del Plata. En el primer capítulo, Marcela Ferrari y Gabriela Closa estudian las estrategias operadas en los partidos políticos mayoritarios de Buenos Aires y Córdoba en la etapa que precedió a la convocatoria electoral nacional de 1983 y la de gobernadores de 1991. El estudio, de carácter comparativo, registra un activo proceso de renovación y transformación en el Partido Justicialista (PJ) y en la Unión Cívica Radical (UCR) a partir de la incorporación de distintos actores en un cambiante escenario político nacional. La propuesta visibiliza los contrastes entre los distritos y las consecuencias políticas del triunfo nacional de la UCR en Buenos Aires y en Córdoba. Así por ejemplo, la victoria de la UCR ubicó al partido y a sus líderes en una posición hegemónica para formalizar acuerdos y alianzas con dirigentes provinciales con injerencia en el plano nacional. En el caso del PJ, los resultados electorales de 1983 determinaron la movilización de las líneas internas y activaron cambios tras la crisis electoral en Buenos Aires y Córdoba. El capítulo II indaga en las causas del rechazo de la ciudadanía a la propuesta de reforma constitucional en la provincia de Buenos Aires en 1989 y 1990. Mariana Pozzoni y Fernando Suárez recuperan uno de los procesos políticos que atravesaron la gran mayoría de estados provinciales en los primeros años de la reconstrucción democrática. La particularidad de la investigación está en la atención que los autores otorgan al impulso reformista considerando los consensos sectoriales y partidarios que planteaban los debates parlamentarios. La investigación se aparta de los análisis de corte reduccionista que focalizan la atención en los objetivos reeleccionistas de Antonio Cafiero, referente del PJ bonaerense. El último capítulo de la Primera Parte, “Normalizaciones regionales. La Confederación General del Trabajo (CGT) de Mar del Plata y Córdoba” presentado por Mónica Gordillo, Carla Sangrilli y Marina Rodríguez analiza la experiencia del sindicalismo y las transformaciones de este sector sin eludir la cuestión de la pesada herencia del movimiento sindical en el nuevo contexto político y social. La denominada normalización se erigió en un ámbito para discutir el carácter de la renovación sindical y habilitó la mediación de distintos dirigentes que aspiraban a conducir el proceso. Asimismo, la originalidad de la propuesta radica en atender a las complejidades regionales (Mar del Plata y Córdoba) para matizar las respuestas formuladas desde los organismos centrales. En sintonía con la opción metodológica adoptada por los compiladores del libro, este trabajo establece puntos de contacto y diferencias entre las experiencias normalizadoras y democratizadoras de los sindicatos en los estados provinciales en vistas de la contienda electoral. Además, ratifica la inconveniencia de aplicar un modelo único para explicar el proceso de recomposición y la articulación con los sectores extra sindicales en la etapa política que se inaugura en 1983.

La Segunda Parte, titulada “Democratizaciones y derechos en disputa”, recupera la intervención de los movimientos sociales y la puesta en práctica de distintas acciones colectivas por la defensa de derechos en un contexto de relaciones sociales en construcción o revisión. La sección está 
encabezada por una investigación de Mónica Gordillo, Ana Elisa Arriaga, María José Franco, Leticia Medina y Ana Carol Solís que explora las notas de protesta publicadas en el diario cordobés La Voz del Interior entre 1984 y 1989 para detectar los signos de conflictividad social. A partir del análisis de los sectores movilizados y las demandas formuladas, los registros revelan que las demandas de ciudadanía laboral dominaron la contienda política provincial. Desde la experiencia del caso cordobés, las autoras proponen la elaboración de una “cartografía de la conflictividad” que conecte los procesos provinciales con la trama nacional para conocer los sectores movilizados, los discursos y las prácticas desarrolladas durante la apertura democrática (p. 124). En esta línea, el siguiente capítulo, “Conflictividad social y articulación política en los barrios cordobeses durante la reconstrucción democrática” de María José Franco, Leticia Medina y Ana Carol Solís, rescata el protagonismo de los barrios y villas de Córdoba mediante el estudio de los reclamos y disputas por la democratización en el acceso a recursos. La movilización en el escenario urbano y la organización de protestas vinculadas al acceso a la tierra, a los servicios y a una reparación de derechos básicos como a la alimentación, la salud y la educación permite a los autores identificar las transformaciones en el tejido social y el tenor de las acciones colectivas en Córdoba.

En el capítulo VI, Mariano D. Fabris complejiza las hipótesis referidas a las continuidades en la etapa de reconstrucción democrática para indagar en el papel de los grupos corporativos, como la Iglesia, a la hora de capitalizar su poder y posicionarse en los debates políticos más importantes de la apertura democrática. Específicamente, el punto de atención está en la discusión referida a la reforma constitucional de la provincia de Córdoba y, específicamente, en el marco de la Asamblea Jurisdiccional del Congreso Pedagógico Nacional donde la Iglesia procuró mantener las concepciones católicas en la discusión de políticas estatales. El papel de la Iglesia y el catolicismo, en el marco de un proceso de secularización, evidencia la conexión existente entre las instituciones eclesiásticas, el Estado y la política.

En "Los prolegómenos de la resistencia. Dos sindicatos eléctricos se posicionan frente al embate neoliberal de los ochenta”, Ana Elisa Arriaga, retoma la dinámica reivindicativa de los sindicatos de Luz y Fuerza de Mar del Plata y Córdoba durante los procesos privatizadores de las empresas públicas de electricidad entre 1987 y 1989. En esta propuesta se visibiliza la reacción ofensiva de los gremios eléctricos ante la ola privatizadora del modelo neoliberal de ajuste y privatización. El capítulo VIII, cierra la sección y analiza la “cuestión de los derechos humanos” en Córdoba y Mar del Plata. En este caso, Ana Carol Solís y Micaela Iturralde, destacan las reformulaciones y especificidades en la actuación de los organismos de derechos humanos para maximizar el éxito de sus reivindicaciones. De esta forma, tanto en Córdoba como en Mar del Plata, se activan distintas lógicas de funcionamiento para motorizar y visibilizar públicamente sus demandas y disputar el contenido de algunas políticas adoptadas por las autoridades constitucionales de la democracia.

Las investigaciones incluidas en el libro La reconstrucción democrática en clave provincial registran los debates, acuerdos y tensiones que protagonizaron distintos actores políticos y sociales durante la posdictadura en Argentina. Desde una perspectiva analítica que recurre al andamiaje teórico y conceptual de la historia, la politología y la sociología, la compilación de Marcela Ferrari y Mónica Gordillo revisa las interpretaciones historiográficas que apelan a una mirada homogeneizadora para explicar los primeros años de la democracia. En su lugar, los distintos capítulos de la obra visibilizan las prácticas, actores y relaciones que subsistieron al cambio 
institucional en los estados provinciales, específicamente, en los casos de Buenos Aires y Córdoba. La obra constituye un original aporte para pensar el pasado reciente en clave provincial, posibilita descentrar la mirada y reconocer la complejidad de los procesos que atravesaron los estados subnacionales. En definitiva, la propuesta considera otras periodizaciones y registra los acuerdos y conflictos durante la reorganización democrática e institucional en los sindicatos y partidos políticos. Asimismo, se comprueban las acciones o respuestas de las agrupaciones barriales, los movimientos de derechos humanos y de grupos corporativos como la Iglesia. En definitiva, el enfoque escogido en este trabajo colectivo, inscrito en la línea de los estudios de Darío Macor y César Tcach (20003 y 2013), permite reconocer la dinámica política provincial sin eludir las conexiones regionales o el influjo del poder central en la planificación de políticas estatales.

\section{Referencias bibliográficas}

O’Donnell, G. (2002). Ilusiones sobre la consolidación. Nueva Sociedad, N 180-181, Jul-Ago / Sep-Oct., pp. 311-332.

Macor, D. y Tcach, C. (2003). La invención del peronismo en el interior del país (T.1). Santa Fe: UNL.

Macor, D. y Tcach, C. (2013). La invención del peronismo en el interior del país (T.2). Santa Fe: UNL.

Smulovitz, C. (2010). Prefacio: La ilusión del momento fundante. En Gargarella R., Murillo M. V. y Pecheny M. (comps.), Discutir Alfonsín, (pp.9-11). Buenos Aires: Siglo XXI. 